panic-reaction described by Lambo (1962) as the " malignant anxiety state"; two cases required to be nursed in a padded room in prison, both being finally unconvicted of sexual offences; the panic reaction appeared to stem directly from the arrest. The precipitation of schizophreniform episodes in prison is also worthy of comment ; five cases illustrated this with sudden hallucinations and delusions, deriving from the stress of imprisonment.

Magistrates seem unable to tolerate much psychiatric disturbance in court. The indifference and inattention of the schizophrenic are sometimes regarded as wanton behaviour, and a mild hypomanic outburst is treated as contempt of court.

\section{Conclusions}

The large majority of men referred for psychiatric report and seen by me in 1963 suffered from schizophrenia (40\%) and personality disorders (39\%). Neurotic states, especially depression and anxiety, were a common complication of psychopathy. Hypomania was not uncommon, nor were panic reactions in coloured men reacting to stress. Social factors contributed to the incidence of criminal behaviour in the mentally ill; the offence was often a cry for help and was committed when the men felt that they needed treatment or when they, or their relatives for them, were unable to obtain it. Ten per cent. of the homeless who were referred had left good homes on account of their illness and had drifted into a state of social isolation, confirming the views of many psychiatrists regarding the drift of schizophrenic patients. The understanding of the mentally ill by police and the courts still seems poor, and the strict operation of the law in regard to these patients appears to be cumbersome. The period in remand in prison might be better used for a fuller psychiatric and social assessment, and treatment facilities in prison seem urgently needed.

The treatment recommended by psychiatrists and prison medical officers is often in the nature of social rehabilitation, which is difficult to arrange from prison, often necessitating hospital admission in the absence of hostel accommodation. The role of the psychiatrist in making recommendations to courts is to suggest disposal of a patient rather than to determine the degree of responsibility for his offence. The number of men coming to the out-patient department after a psychiatric interview in prison but without a specific recommendation for treatment being made to the courts is noteworthy. Many more of those with personality disorders could have been admitted to hospital at the time had treatment facilities been available.

\section{Summary}

A study of 146 consecutive men who were referred from courts and prisons for a psychiatric opinion in one year is reported. Medical and social aspects are discussed. The most common diagnostic categories were schizophrenia (40\%) and personality disorders (39\%)-the latter often associated with neurotic reactions. Frequently more than one diagnosis was made; or an intractable social problem was apparent which seemed to contribute to the criminal behaviour. Possibly an increasing number of psychopaths are being referred because of the provisions of the Mental Health Act, 1959.

In $77 \%$ a previous psychiatric history was found, and $43 \%$ had been given a previous prison sentence. Six per cent. were newly diagnosed schizophrenics: a number of floridly ill men had spent many years in prison without treatment.

The offences committed were usually of nuisance value only, except for six which were very serious. The majority of men were offered some form of psychiatric help, and in general the recommendation for treatment was accepted by the court; in a few cases where it was not accepted the patients needed to be admitted to hospital shortly afterwards, often during a prison sentence. I questioned the need for so many men being remanded in custody for a psychiatric report.

\section{REFERENCES}

Brooke, E. M. (1962). Lancet, 2, 1211.

Hewitt, L. E., and jenkins, R. L. (1946). Fundamental Patterns of Maladjustment. Springfield.

Lambo, T. A. (1962). 7. ment. Sci., 108, 256.

Mayer-Gross, W., Slater, E., and Roth, M. (1954). Clinical Psychiatry. Cassell, London.

Rollin, H. R. (1963). Brit. med. 7., 1, 786.

Sco (1965). Ibid., 1, 831.

Scott, P. D. (1960). Ibid., 1, 1641

West (1964). Ibid., 1, 1117.

West, D. J. (1963). The Habitual Prisoner. Macmillan, London.

Bearcroft, J. S., and Smith, A. (1960). Int. F. soc. Psychiat., 6, 34.

\title{
Thyrotoxicosis and Gigantism Associated with "Klinefelter's Syndrome"
}

\author{
RAYMOND GREENE,* D.M., F.R.C.P. ; WILLIAM SINGER,* M.B., B.S.
}

Brit. med. F., 1965, 2, 1523-1525

Abnormally rapid growth occurs sometimes in thyrotoxicosis but is uncommonly the major symptom. The combination of gigantism and thyrotoxicosis has not previously been described in association with a chromosomal abnormality.

\section{Case Report}

The patient, a white boy of 15 , was brought to the clinic because of excessive growth and retarded sexual development. He complained of dyspnoea on exertion but had no other symptoms of thyrotoxicosis. Scholastically he was about three years behind his contemporaries. As a child he had been lethargic: he first walked at $2 \frac{1}{2}$ and first talked at $3 \frac{1}{2}$ years. He had not suffered from any serious illnesses. He had grown 8 in. $(20 \mathrm{~cm}$.) in two years, the normal increase in this period being from 5 to 6 in. $(12.5$ to $15 \mathrm{~cm}$.).

* Department of Endocrinology, New End Hospital, London.
On examination he was a very thin boy, 76 in. $(193 \mathrm{~cm}$.) in height and weighing $121 \mathrm{lb}$. $(54.9 \mathrm{~kg}$.). The normal height for his age (Polani's chart) was 56 to 71 , average $64 \frac{1}{2}$ in. (142 to 180 , average $164 \mathrm{~cm}$.). He had pectus excavatum. The penis was small and the testicles were soft and the size of cherries. The pubic hair was sparse and of feminine distribution. There was no facial or axillary hair. The thyroid was just palpable. The pulse rate was 93 . There were no other features suggestive of thyrotoxicosis.

Investigations.-Serum protein-bound iodine (P.B.I.) $11.6 \mu \mathrm{g} . /$ $100 \mathrm{ml}$. $\mathrm{T}_{3}$ (red-cell uptake) $25.7 \%$ (normal 15-20\%). " $\mathrm{T}$ " (urinary excretion of ${ }^{131} \mathrm{I}$ ) $100+$ (normal 3-13). B.M.R. $+23 \%$. Urinary steroids: 17-ketosteroids $5.8 \mathrm{mg} . / 24$ hours, 17-hydroxycorticosteroids $21.2 \mathrm{mg} . / 24$ hours. Urinary follicle-stimulating hormone (F.S.H.) 96-384 mouse units/24 hours. The bone age corresponded with the chronological age.

He was thought to be suffering from thyrotoxicosis, exhibiting an unusual rate of growth with curiously few features suggestive of this diagnosis. As there were signs of early puberty, it was decided not to treat his hypogonadism at this stage. 
For the next three years he was treated with carbimazole (Neomercazole), which kept him euthyroid but led to a gradual symptomless enlargement of his thyroid. $\mathrm{He}$ was admitted to hospital for reassessment at the end of July 1964, when he was quite asymptomatic. Examination on this occasion showed: height 78 in. $(198 \mathrm{~cm}$.) (no growth had taken place for the previous nine months), weight $143 \mathrm{lb}$. (64.9 kg.), and span 78 in. (198 cm.) (upper measurement 36 in. $(91 \mathrm{~cm}$.), lower $42 \mathrm{in} .(107 \mathrm{~cm}$.) ). He was thin, but showed average strength. His behaviour was rather childish and his intelligence somewhat low. His voice had broken but was still rather high. There was facial acne. The testicles had not changed in size since he was first seen in 1961. The pubic hair was of female distribution, and some hair was present in the axillae and on his limbs. There was no facial hair. He had a large smooth firm goitre with a bruit over the gland. There were no pressure signs or symptoms.

Investigations.-Thyroid-function tests were at the upper limit of normal. Thyroid antibodies (thyroglobulin-tanned-red-cell and complement-fixation tests) were negative. His bone age was about one year below his chronological age. Urinary steroids: 17-ketosteroids $13.1 \mathrm{mg} . / 24$ hours, 17-hydroxycorticosteroids $21 \mathrm{mg} . / 24$ hours. A buccal smear showed $17 \%$ sex-chromatin-positive cells. Chromosome analysis (Professor Polani) showed an XXY picture.

Carbimazole was discontinued (after 39 months' treatment) and he relapsed into a thyrotoxic state within six weeks (serum P.B.I. $8.5 \mu \mathrm{g} / 100 \mathrm{ml} ., \mathrm{T}_{3}$ (resin uptake) $133 \%$ (normal 90-110\%).

A partial thyroidectomy was performed (Mr. J. E. Piercy) on 5 October 1964. Histological examination showed epithelial hyperpirsia. He was given an implant of $1 \mathrm{~g}$. of testosterone.

\section{Discussion}

This patient showed two unusual features: (1) greatly increased growth between the ages of 13 and 15 in a boy with thyrotoxicosis, with few other symptoms or signs of hyperthyroidism ; and (2) the association of the thyroid disorder with hypogonadism, a high urinary F.S.H. level, and an XXY chromosome picture ; a triad which justifies the label of " Klinefelter's syndrome" despite the absence of gynaecomastia and testicular histology (Heller and Nelson, 1945). At first hand this combination could be dismissed as a chance association, as the incidence of Klinefelter's syndrome has been estimated at between 1 in 400 and 1 in 1,000 of male births (New Engl. 7 . Med., 1963) and thyrotoxicosis in childhood is not uncommon, constituting some $1-2.5 \%$ of thyrotoxics in the series reported by Atkinson (1938), and $5 \%$ in that reported by Saxena et al. (1964). The female:male ratio varied from 4 to 1 (Saxena et al., 1964) to 11 to 1 (Bartels, 1949) in different series. The high preponderance of females applies, of course, to all thyroid diseases. For this reason one might expect an increased incidence of thyroid disorders in individuals possessing two or more X chromosomes.

Surprisingly few cases of gigantism associated with hyperthyroidism have been described in the literature. Randle (1959) claimed that, though thyroxine is necessary for normal growth, excess of thyroxine does not produce accelerated growth. Tata (1964), quoting the findings of several workers (Vidgoff and Stampfer, 1950; Gross and Pitt-Rivers, 1953), states that, both experimentally and clinically, small doses of thyroxine restore or accelerate normal growth, but large amounts " mask this effect or even markedly suppress growth." The generally held view quoted in the British Medical fournal (1958) seems to be that, though thyroxine by itself does not promote growth, it acts as a stimulator of growth hormone, so that rapid bone growth and accelerated skeletal development take place (Zor et al., 1965). Thyroxine is incapable of accelerating growth in hypophysectomized animals (Paschkis et al., 1958). Zeckwer et al. (1935) showed that thyroidectomy produced a loss of anterior pituitary eosinophil cells, which, however, reappeared after administration of thyroxine (Moncrieff, 1947 ; Schlesinger and Fisher, 1951; Wilkins, 1957). Hubble (1957) claims good effect on growth in an uncontrolled trial by using thyroxine together with testosterone in hypopituitary dwarfism. Experi- mental work on the rat by Ray et al. (1954) (quoted in Brit. med. F., 1954) showed, however, that thyroxine had little effect on growth but brought about skeletal maturation.

Bartels (1949) reports 12 juvenile cases of thyrotoxicosis out of 1,000 seen at the Lahey Clinic. Eleven of these were females and only three were in the 13 to 15 age group. The diagnosis in this group did not present a great problem, as either goitre or exophthalmos or both were present in most of them. Only a slight increase in the rate of growth was present. In a recent study by Saxena et al. (1964) 70 juvenile thyrotoxics were studied. This group constituted $5 \%$ of the total number of cases of thyrotoxicosis seen, and $79 \%$ of these were females. They, too, noted an increased rate of growth, particularly in the under-10 group. However, in no case was excessive growth the presenting symptom.

An association between Klinefelter's syndrome and thyroid abnormalities has been reported. Burt et al. (1954) reported a case of Klinefelter's syndrome associated with a nodular goitre containing microfollicular adenomata. They also reviewed 21 further cases of Klinefelter's syndrome (Brit. med. F., 1958), $6(28 \%)$ of which had an enlarged thyroid, half of these showing a histological picture of microfollicular adenomata. All of these 22 patients were apparently euthyroid. Davis et al. (1963) report four XXY individuals, three of whom had a low ${ }^{131} \mathrm{I}$ uptake. In March 1963, at a clinicopathological conference held at the Hammersmith Hospital, a case of Klinefelter's svndrome was shown in which a nodular goitre was found incidentally at post-mortem examination (Brit. med. F., 1963). The radioiodine uptake in this case was normal. Fraser (1963) claims that there is an increased frequency of non-toxic goitres in XXY individuals, without giving details of his series. Barr et al. (1960) studied 15 chromatin-positive males and noted a low radioiodine uptake and a poor response to thyroidstimulating hormone (T.S.H.) in the entire group. The studies of Jones et al. (1941), Koller and Siegenthaler (1955), and Davis et al. (1963) confirmed these findings in investigations of small groups of patients. Boyle and McGirr (1965) described a case of athyroidal cretinism associated with Klinefelter's syndrome.

Plunkett et al. (1964) studied 27 cases of Klinefelter's syndrome: $17(63 \%)$ of these showed a radioiodine uptake of less than $15 \%$. A poor T.S.H. response was recorded in $47 \%$. Oddly enough the protein-bound-iodine levels were found to be normal in all but five patients. Similar results were obtained in female triple-X and tetra-X cases. As all but three of the 27 patients studied were mentally subnormal, it was suggested that the relationship could be explained either on the basis of mental retardation (though a control group of patients in a mental hospital showed a normal radioiodine uptake) or on the basis of abnormal genes carried on the extra $\mathrm{X}$ chromosomes. All these patients were apparently clinically euthyroid and showed no thyroid enlargement. A low radioiodine uptake, poor T.S.H. response, and normal protein-bound iodine might, of course, be due to little functioning thyroid tissue working at full capacity. In none of these studies was a single case reported of Klinefelter's syndrome associated with thyrotoxicosis.

\section{Summary}

A case is described of juvenile thyrotoxicosis, rapid growth, and hypogonadism in a patient with an XXY constitution. The syndrome has not been previously reported.

This case was presented at a clinical meeting of the Section of Endocrinology of the Royal Society of Medicine. We are grateful for permission to publish it.

\section{REFERENCES}

Atkinson, F. R. B. (1938). Brit. 7. Child. Dis., 35, 165.

Barr, M. L., Shaver, E. L., Carr, D. H., and Plunkett, E. R. (1960). , M. ment.' Defic. Res., 4, 89.

Bartels, E. C. (1949). Lahey Clin. Bull., 6, 68.

Boyle, J. A., and McGirr, E. M. (1965). Brit. med. F., 1, 1170. 
Brit. med. 7., 1954, 2, 748.

$1963,1,866$.

1958, 1, 567.

Burt, A. S., Reiner, L., Cohen, R. B., and Sniffen, R. C. (1954). F. clin. Endocr., 14, 719.

Davis, T. E., Canfield, C. J., Herman, R. H., and Goler, D. (1963). New Engl. .. Med., 268, 178.

Fraser, G. R. (1963). Brit. med. F., 1, 1284.

Gross, J., and Pitt-Rivers, R. (1953). Biochem. F., 53, 652.

Heller, C. G., and Nelson, W. O. (1945). J. clin. Endocr., 5, 1.

Hubble, D. (1957). Brit. med. F., 1, 601

Jones, R., McCullagh, E. P., McCullagh, D. R., and Buckaloo, G. W. (1941). F. clin. Endocr., 1, 656.

Koller, F., and Siegenthaler, W. (1955). Schweiz. med. Wschr., 85, 8.

Moncrieff, Z. E. (1947). Postgrad. med. F., 23, 39.

New Engl. f. Med., 1963, 268, 215.

Paschkis, K. E., Rakof, A. E., and Cantarow, A. (1958). Clinical Endocrinology, 2nd ed., p. 131. Hoeber, New York.
Plunkett, E. R., Rangecroft, G., and Haegy, F. C. (1964). ¥. ment. Defic. Res., 8, 25.

Randle, P. J. (1959). Med. Press, 242, 211.

Ray, R. D., Asling, C. W., Walker, D. G., Simpson, M. E., Li, C. H., and Evans, H. M. (1954). 7. Bone Ft. Surg., 36A, 94.

Saxena, K. M., Crawford, J. D., and Talbot, N. B. (1964). Brit. med. f., 2, 1153.

Schlesinger, B., and Fisher, O. D. (1951). Lancet, 2, 289.

Tata, S. R. (1964). Action of Hormones on Molecular Processes, edited by $G$. Litwack and D. Kritchevsky, pp. 60, 61. Wiley, New York. Vidgoff, B., and Stampher, J. (1950). West. J. Surg., 58, 20.

Wilkins, (1957). The Diagnosis and Treatment of Endocrine Disorders in Childhood and Adolescence, 2nd ed., p. 137. Thomas, Disorders in Chingeld, Ill.

Zor, V., Dikstein, S., and Sulman, F. G. (1965). F. Endocr., 32, 35.

Zeckwer, I. T., Davison, L. W., Keller, T. B., and Livingood, C. S. (1935). Amer. F. med. Sci., 190, 145.

\title{
Cytology and the General Practitioner
}

\author{
T. R. CULLINAN,* M.B., B.CHIR., M.R.C.o.G.; B. A. MONTGOMERY,* M.B., в.CH., B.A.O.
}

Brit. med. F., 1965, 2, 1525-1527

Despite publicity in the popular press and radio over the last few months, many general practitioners have been surprised at how few of their patients have demanded a cytological smear test for the detection of cervical carcinoma-in-situ.

In the following survey an attempt has been made to gauge the response of patients to a free, easily available cytological screening service for uterine cancer, and to classify the findings, microscopical and macroscopical, as well as public attitude. The population to whom this service was offered constituted the 20-to-80-year age group of female patients of one general practice in South-east England during the months from June 1964 to December 1964. All slide-taking, staining, and microscopy was undertaken by the two partners concerned in the study, one of whom (T.R.C.) had had the necessary training for slide screening. Doubtful slides were referred to Dr. E. Wachtel, of Hammersmith Hospital, who kindly offered to be referee.

\section{Purposes of the Study}

The purposes of the study were as follows: (1) to gauge public enthusiasm, apathy, and fear, and to try to correlate these with the socio-economic groups of the patients concerned; (2) to screen as many women as possible, and to get as many as possible used to accepting the smear test as a regular threeyear one ; (3) to record any incidental microscopical and macroscopical findings and to offer treatment where necessary ; (4) to try to assess the role of the general practitioner in any future survey.

\section{Practice Population}

The practice is basically a mixed urban and rural practice, involved in light industry, farming, and commuting to work in London. It also includes a growing housing estate with a considerable number of young families from London on an "over-spill" plan. The total number of patients is about 6,000 , predominantly working class ; of this number there are 1,984 women in the 20 -to- 80 -year age group, and it is of these that the survey is made up. Table I shows the approximate socio-economic grouping of these women.

Because of the wide range of ages these figures obviously show a fair number of poor, elderly people, some of whom are

* General Practitioner, Ashford, Kent.

D bed-ridden or confined to their homes; and Group $\mathrm{V}$ is perhaps larger than a country-wide survey would reflect, because of the existence in the neighbourhood of a large gipsy camp.

TABLE I.-Approximate Socio-economic Grouping of Women in 20-to80-year Age Group

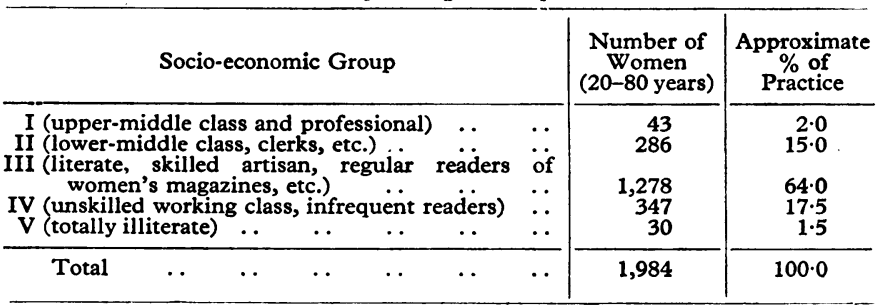

\section{Organization of Survey}

A small, unalarming but very easily noticed poster explaining the importance of the test and announcing its availability was put up in the waiting-room of each of the two surgeries in the practice at the end of May 1964. (This happened to coincide with a mild surge of interest in vaginal cytology in some of the popular women's magazines.) The wording of the poster was as follows:

"Two thousand five hundred women die every year in Great Britain from cancer of the neck of the womb. Yet this disease is now almost totally preventable by a quick, simple, painless test repeated at two- or three-year intervals. We are now in a position to offer this test free to all our female patients, and you are most earnestly advised to think about this. Please ask the doctor for more information."

Without any doubt most of the patients in the waiting-rooms saw the posters or had them pointed out to them by friends. It has been estimated, from a random sample of 400 record cards, that about $55 \%$ of patients in the age group involved visited the surgeries, and therefore came into theoretical contact with the posters, during the period of the survey-June to December 1964.

For the purposes of the survey those patients who had slides taken were divided into four categories:

A. Those who asked, entirely spontaneously, for the test to be performed as a result of reading the posters (plus a very fewabout four-who had asked before the scheme began). 